\title{
O significado e a vivência do abandono familiar para presidiárias
}

\section{The meaning and the experience of abandonment to family prisoners}

\author{
Amanda Costa Freitas de Jesusa, Lannuzya Veríssimo e Oliveirab ${ }^{b}$ Eloide André Oliveirac, \\ Gisetti Corina Gomes Brandão ${ }^{d}$, Gabriela Maria Cavalcanti Costae \\ a Enfermeira graduada pelo Curso de Enfermagem da Universidade Estadual da Paraíba (UEPB), Campina Grande, PB, Brasil.

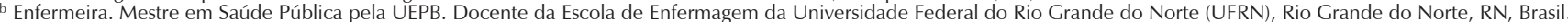 \\ c Enfermeira. Mestre em Enfermagem pela Universidade Federal da Paraíba. Docente do Curso de Enfermagem da UEPB, Campina Grande, PB, Brasil. \\ d Enfermeira. Doutorado em Enfermagem pela Universidade de São Paulo. Docente do Curso de Enfermagem da Universidade Federal de Campina Grande (UFCG) \\ Campina Grande, PB, Brasil. \\ e Enfermeira. Doutorado em Enfermagem pela Universidade de São Paulo. Docente do Curso de Enfermagem da UEPB, Campina Grande, PB, Brasil.
}

RESUMO

Objetivo: Compreender o significado e a vivência do abandono familiar para presidiárias.

Materiais e Métodos: Trata-se de um estudo qualitativo descritivo e exploratório realizado em duas penitenciárias femininas da Paraíba, no período de julho a outubro de 2013. Para coleta de dados foram utilizados um questionário sociodemográfico e uma entrevista semiestruturada realizada com 13 presidiárias. Os dados foram analisados conforme técnica da Análise de Conteúdo.

Resultados: Duas categorias foram evidenciadas: significado da família para presidiárias e abandono familiar.

Conclusão: Apreendeu-se que para as entrevistadas a família representa um importante suporte afetivo e elo social, de modo que o abandono familiar no período do aprisionamento associa-se ao sofrimento, ao desamparo e a solidão, e vivenciá-lo interfere na qualidade de vida da presidiária, interferindo no processo de ressocialização.

PAlAVRAS-ChAVE: Relação familiar. Mulheres. Prisões.

Objective: To understand the meaning and the experience of family abandonment to prisoners.

Materials and Methods: This is a descriptive and exploratory qualitative study conducted in two female prisons in Paraiba, in the period from July to October 2013. For data collection we used a demographic questionnaire and a semi-structured interview with 13 prisoners. Data were analyzed using content analysis technique.

Results: Two categories were found: family meaning for prisoners and family abandonment.

Conclusion: The analysis showed that family is an important emotional and social support link for the prisoners, so the family abandonment during imprisonment is associated with suffering, helplessness and loneliness, and the experience interferes with the quality of life of prisoners, altering in the rehabilitation process.

KEYWORDS: Family relations. Women. Prisons. 


\section{INTRODUÇÃO}

Existem atualmente 34.058 mulheres presas no Brasil, o que representa cerca de $7 \%$ do total da população penitenciária do país. Ainda que representem minoria dentre a população carcerária, o aumento do número de presidiárias no último triênio foi de $32,73 \%$, enquanto a média de crescimento masculino no mesmo período foi de $15,37 \%{ }^{1}$.

O perfil dessas mulheres é composto predominantemente por jovens, afrodescendentes, com baixo nível socioeconômico, mães-solteiras e com média de três filhos² . Entretanto, com a separação decorrente do aprisionamento, por vezes, ocorre a fragmentação dos vínculos familiares e a perda dos papéis sociais atribuídos ao feminino: o de mãe e de esposa ${ }^{3}$.

A família é considerada um grupo primário tão antigo quanto a própria história da espécie humana, e dessa forma suas funções, características e papéis foram se modificando ao longo do tempo, sob o peso de inúmeras alterações socioeconômicas, culturais e políticas. Todavia, a família ainda mantém forte influência na educação, socialização e no processo de desenvolvimento físico, psicológico e emocional para todos que a constitui ${ }^{3}$.

Assim, como consequência do rompimento dos vínculos familiares devido ao aprisionamento, ocorre o abandono familiar que é compreendido como processo de descaso e desamparo causado a um indivíduo por um ou mais membros de sua família ${ }^{3}$.

Constitui-se fatores que predispõe o abandono familiar às dificuldades socioeconômicas vivenciadas pelos familiares das presidiárias, a distância das prisões femininas, o constrangimento causado pelas revistas que precedem a entrada no ambiente prisional associado aos estigmas causados para os que ficam em portas de cadeia, além do tempo diminuto para as visitas o que limita o convívio ${ }^{4}$. Ademais, acrescente-se as questões de gênero, visto que no contexto do aprisionamento feminino o abandono familiar é situação recorrente, diferentemente da realidade vivenciada pelos homens presos, os quais, em sua maioria, recebem apoio familiar durante todo o cumprimento da pena ${ }^{5}$.

Sabe-se também que em situação de vulnerabilidade, física, mental ou social, o apoio familiar é primordial para manutenção da qualidade de vida e/ou na recuperação do indivíduo6. Destarte, o abandono familiar vivenciado no âmbito prisional, ambiente este reconhecidamente insalubre, corrobora com a diminuição da qualidade de vida dos presidiários ${ }^{7}$. Todavia, são escassas as publicações, sobretudo nas ciências da saúde, que abordem aspectos referentes ao abandono familiar e a saúde da mulher presa.
Mediante tais considerações e em cumprimento as diretrizes da Agenda Nacional de Prioridades de Pesquisa em Saúde ${ }^{8}$, no tocante ao desenvolvimento de pesquisas que abordem o acesso e qualidade da atenção à saúde das mulheres no sistema prisional desenvolveu-se este estudo cujo objetivo foi compreender o significado e a vivência do abandono familiar para presidiárias.

\section{MATERIAIS E MÉTODOS}

Estudo de caráter descritivo e exploratório com abordagem qualitativa, realizado entre os meses de julho a outubro de 2013 em duas penitenciárias femininas do sistema prisional subordinada à Secretaria de Estado da Cidadania e Administração Penitenciária da Paraíba: O Instituto de Recuperação Feminina Maria Júlia Maranhão João Pessoa e a Penitenciária Feminina de Campina Grande, que abrigavam respectivamente, neste período, 259 e 69 mulheres em regime fechado.

Com base no desenho da abordagem qualitativa, optou-se pelo processo de amostragem por saturação das informações, que indica a interrupção na coleta de dados quando se constata que elementos novos para subsidiar a teorização almejada não são mais desprendidos a partir do campo de observação ${ }^{9}$. Sendo a amostra encerrada em 13 entrevistadas. Elegeu-se como critérios de inclusão: mulheres reclusas, cumprindo pena em regime fechado que não receberam visitas de familiares a um período maior ou igual há seis meses.

Após a permissão para a realização da pesquisa através de assinatura do Termo de Consentimento Livre e Esclarecido (TCLE) as mulheres foram entrevistadas mediante agendamento de dia e horário adequado, de acordo com a dinâmica da penitenciária. Como instrumento de coleta de dados foi utilizado um questionário sociodemográfico para caracterizar os sujeitos da pesquisa e uma entrevista semiestruturada.

As entrevistas foram realizadas de forma individual, sendo audiogravadas para evitar interrupções e compreensões equivocadas. A análise das falas seguiu a proposta metodológica de Bardin, que utiliza a modalidade categorial temática, onde as falas das entrevistadas foram transcritas integralmente e, posteriormente, classificadas por temas centrais presentes nos relatos. Os objetivos da pesquisa nortearam o agrupamento dos temas centrais e, embasado no referencial teórico disposto, realizaram-se as três fases da análise de conteúdo: a pré-análise, a exploração do material e o tratamento dos resultados ${ }^{10}$.

Esta pesquisa foi aprovada pelo Comitê de Ética em Pesquisa da Universidade Estadual da Paraíba, sob o Certificado de Apresentação para Apreciação Ética - CAAE 
no 01340133000-12, e obedeceu aos critérios da resolução $466 / 12$, onde as entrevistadas foram esclarecidas sobre o objetivo e benefícios do estudo e assinaram o Termo de Consentimento Livre e Esclarecido (TCLE). A fim de resguardar o anonimato dos sujeitos da pesquisa foram utilizados pseudônimos.

\section{RESULTADOS E DISCUSSÃO}

\section{Caracterização dos sujeitos da pesquisa}

As entrevistadas eram predominantemente jovens, na faixa etária de 18 e 25 anos, casadas, com média de três filhos, possuíam o ensino fundamental incompleto, católicas e afirmaram morar com a família antes do aprisionamento, sendo o tráfico de drogas a principal causa de aprisionamento.

\section{Categorias temáticas}

Através da análise das falas emergiram duas categorias: 1. Significado da família para presidiária e 2. Abandono Familiar, com as suas subcategorias: 2.1 Significado do abandono familiar e 2.2 Vivência do abandono familiar. A primeira categoria apresenta a compreensão das entrevistadas acerca do significado de família e a segunda categoria aborda o significado do abandono familiar e como este abandono é vivenciado pelas entrevistadas.

\section{Significado da família para presidiárias}

A família é definida como um conjunto de pessoas ligadas por parentesco ou dependência, que estabelecem entre si relações de solidariedade, tensão, conflito e afeto ${ }^{6}$.

Entretanto, ao longo dos séculos, a família vem passando por modificações concernentes à composição, tamanho, funções, valores, costumes e distribuição interna de papéis e de poder conforme a exigência social de cada época, o que torna complexa a tarefa de conceituar e entender a organização familiar no decorrer da história ${ }^{11}$.

Por este motivo, autores afirmam que a família não é uma expressão passível de conceituação, mas tão somente de descrições; ou seja; é possível descrever as várias estruturas ou modalidades assumidas pela família através dos tempos, mas não defini-la ou encontrar algum elemento comum a todas as formas com que se apresenta este agrupamento humano ${ }^{12}$.

Todavia, comumente a significação dada a família associase ao suporte afetivo, emocional, responsável pela harmonia e equilíbrio do individuo ${ }^{13}$. Significações semelhantes são apresentadas pelas participantes deste estudo, conforme observa-se nas falas que seguem:
"Pra mim família é a base de tudo na vida de um ser humano [Choro]. Você receber carinho, dar. É tudo." (Lírio)

"É tudo. A minha família é muito especial para mim é a minha base. Sem a minha família eu não sou ninguém." (Girassol)

“É tudo para mim. Graças a Deus mesmo tendo feito muita burrada minha família estava comigo ali sabe. Tinha muita amizade com meu pai, mãe e com meus irmãos." (Gardênia)

A compreensão da família enquanto alicerce de vida é explicado pelo o fato do ser humano desenvolver suas primeiras experiências enquanto membro da sociedade no seio familiar ${ }^{14}$. Além disso, a família é o lugar indispensável para a garantia da sobrevivência e da proteção integral dos filhos e demais membros, independentemente do arranjo familiar ou da forma como vêm se estruturando. É quem propicia o aporte afetivo e, sobretudo o material necessário ao desenvolvimento e bem-estar dos seus componentes, estando estes sempre presentes na memória das entrevistadas ${ }^{15}$.

Tendo compreensão semelhante aos autores, as apenadas descrevem em suas falas a importância do apoio familiar em todas as circunstâncias, principalmente nas situações caracterizadas por elas como as mais difíceis:

"E eles são o que ajuda nóis a enfrentar as coisa difícil da vida." (Açucena)

"Família para mim tá nas horas mais difíceis ao lado da pessoa." (Flor de-Lis)

Portanto, é preciso considerar que para uma presidiária, a família se revela a base reguladora, e o seu empenho em sair da prisão está diretamente relacionado e influenciado pelo suporte que recebe ${ }^{16}$. Pois, a presença familiar é considerada porto seguro, capaz de ofertar suporte emocional, educativo, econômico e social indispensáveis no período de aprisionamento ${ }^{17}$.

Este estudo corrobora para demonstrar que para as participantes deste estudo, a família representa uma âncora que as mantêm conectadas à realidade do mundo fora da instituição, e que o alento dos familiares proporciona estímulo para o enfrentamento de sua pena e, quando da saída do presídio, nova vida fora da marginalidade ${ }^{16}$.

\section{Abandono familiar}

Abandono familiar é referido como um sentimento de sofrimento trazido pelo processo de aprisionamento, o que impede a pessoa de viver e conviver plenamente e 
de permanecer inserido na sua família, no seu grupo e na sua cultura, rompendo assim o contato vital com o mundo. O estar-indefeso, a falta de intimidade compartilhada e a pobreza de afetos e de comunicação tendem a mudar estímulos de interação social e de interesse com a própria vida $^{18}$.

\subsection{Significado do abandono familiar}

Identifica-se que a manutenção da relação familiar é considerada de grande importância para as presidiárias, capaz de minimizar a saudade e o sofrimento causados pelo encarceramento, conforme se apreende na fala que segue:

"É um sofrimento e uma saudade muito grande, ficar aqui sem receber visita da família (Choro). É muito triste ficar aqui abandonada, sozinha e sem a família, por isso temos que dar valor a família da gente." (Girassol)

Torna-se relevante considerar também a estigmatização social experimentada pela mulher que comete um delito, tal estigmatização, por sua vez, dá-se, indiscutivelmente, pela herança histórica das sociedades patriarcais, que apregoava a submissão e recato feminino, logo as mulheres que contrariam tal premissa são punidas e marginalizadas socialmente, fator que contribui decisivamente para o abandono da presidiária pela família e amigos ${ }^{19}$. Acrescente-se ainda que, o envolvimento com a criminalidade pode desencadear uma ruptura familiar que precede o encarceramento ${ }^{20}$.

Por compreender as dificuldades em manter os vínculos familiares, ao mesmo tempo em que as presidiárias procuram desenvolver uma relação mais estreita com os membros da família, veem com ceticismo a possibilidade de reatar as relações ou os laços quando se encontrarem fora dos muros da prisão ${ }^{21}$.

Para algumas entrevistadas o abandono familiar significa solidão, isolamento do "mundo externo" e incompreensão por parte dos familiares, como nota-se nas falas a seguir:

“Não ter notícias de ninguém, ficar aqui sem saber de nada da família nem do que ta acontecendo lá fora. É muito triste." (Girassol)

"É a família virar as costas. Sinto isso na pele tem três anos. Dói na carne... sabe como é. Eles nem vem, nem manda notícia... parece que abriu e fechou o mundo e eles sumiram." (Açucena)

"Abandonar uma coisa é deixar para lá. É não querer mais. É ficar longe..." (Dália)

Estudos afirmam que as presidiárias queixam-se da ausência de familiares nas horas de aflição, medo e insegurança inerentes do cárcere, situação que se acentua principalmente nos casos de presidiárias primárias $^{16}$. Acrescente-se que o desamparo suscita mágoas entre as entrevistadas e as famílias, como sugere a seguinte fala:

"É a família vira as costas para alguém. Seja criança, adulto, velho... qualquer um pode ser abandonado. E acho que em qualquer tempo da vida de uma pessoa quando acontece de ser abandonado deixa marca." (Tulipa)

"A pessoa se sente só, parece que não tem ninguém por mim." (Flor-de-lis)

Nesse sentido, a sensação de solidão é compreendida e referida pelas mulheres presas, visto que, o abandono do companheiro e o distanciamento da família são quase inevitáveis neste contexto ${ }^{22}$.

Deste modo, percebe-se que o abandono familiar atua negativamente na qualidade de vida das presidiárias, acentuando as dificuldades no cárcere. Ademais, o rompimento dos laços afetivos, não raras vezes, perpassa o período de aprisionamento, o que implica em maiores dificuldades para ressocialização das presidiárias, uma vez que a ressocialização esta sumariamente associada à oferta de suporte afetivo, social e econômico ${ }^{23}$.

\subsection{Vivência do abandono familiar}

São muitos os problemas enfrentados pelas presidiárias, mas a separação dos familiares destaca-se como um dos maiores sofrimentos durante o cumprimento da pena ${ }^{23}$. Sofrimento este que são apresentados nas falas que seguem:

"É um desespero, um vazio, uma dor, (Choro) más às vezes agente tem que passar por isso pra aprender. Não tem nem mais como expressar sobre isso porque é uma dor na vida e quando eu falo neles é onde me preenche o vazio (choro). Não tem nem como expressar." (Flor-de -laranjeira)

"Que quem é abandonado sofre do lado do sentimento e do lado de não ter nada. Aqui na prisão a gente não tem nada. Então quem recebe visita e tem família para apoiar tem algumas coisas garantidas." (Açucena)

"Aqui dentro tudo doi mais. Tudo é pior. Porque se vc é abandondado la fora, pode sair passear, vê gente... e aqui o tempo para. A vida nao segue e quando não vem ninguém é muito ruim. Ser abandonado é ruim. A gente se sente bicho." (Gardênia)

"A pessoa se sente sozinha." (Orquídea) 
Não vou dizer que não sofro. Sofro muito, mas, eu escolhi isso. então ser presa significa ser abandonada pela família sim. Para mim mesmo aquela que recebem visita nos dias de visita são abandonadas. Porque a relação muda sabe." (Tulipa).

Torna-se pertinente considerar também o sofrimento vivenciado pelos familiares do preso, sobretudo no tocante aos réus primários, visto que o aprisionamento é fonte vergonha, raiva, indignação e mágoa para os familiares e para o preso $^{16}$. Tal assertiva converge com o trecho seguinte:

“Eu acho duro, duríssimo (Choro) duro pra quem ta lá fora e duro pra que tá aqui dentro né? Porque lá fora o tempo passa." (Copo-de-leite)

De fato, quando algo inesperado ocorre com um membro da família, toda a família sofrerá a mudança. Isso se explica pela relação da função adaptativa da família ter início já em seu interior a ação de assumir determinados papéis relacionados pelos seus membros ${ }^{4}$. Quando a família ou um de seus membros não conseguem cumprir o seu papel social e falha nessa função, seja por tragédias intensas como as guerras, ou por desestruturação da família nuclear, como morte do pai/mãe, separação/divórcio, doença e/ou aprisionamento; o indivíduo pode ter seu processo de adaptação (socialização) comprometido ${ }^{4}$.

Quanto aos fatores que predispõe o abandono familiar, destacam-se os rígidos preceitos morais que envolvem o feminino, uma vez que a mulher ainda é vista como uma representação de moralidade e religiosidade presentes no percurso histórico das prisões femininas brasileiras ${ }^{3}$ e, àquelas que contrariam as premissas de moral e bons-costumes cabíveis a mulher são marginalizadas e dificilmente perdoadas, inclusive por suas famílias. Assim, para as participantes deste estudo, o envolvimento com a criminalidade é fator primordial para o abandono familiar por elas vivenciado, conforme sugere nas falas:

“Dinheiro não é. É porque o que dificulta foi eu fazer o que o crime que eu cometi, porque minha família não aceita. Uma coisa que eu sei que eles não vão aceitar nunca." (Flor-de-Laranjeira)

"É geralmente é pelo o que a pessoa fez, isso também ajuda. E eles tem ficado muito decepcionado comigo ter caído aqui dentro, aí isso dificulta muito." (Lírio)

"Porque ela (mãe) falava que se eu caísse de novo ela não ia vim." (Margarida)

"Eu sei mesmo que minha família sumiu e me abandonou aqui por tudo que eu fiz. Isso foi o que causou o meu abandono. Eles cortaram eu de vez sabe. Nem vem aqui." (Açucena)
Já na fala a seguir a presidiária refere que uma das possíveis causas para o abandono familiar é o fato da relação existente anteriormente ao aprisionamento já ser desgastada, o que contribui diante desta situação para que os laços entre a família se tornem cada vez mais desfeitos:

"Eu penso que duas coisas pode ter relação com o abandono da família quando a pessoa tá presa: a relação que tinha antes e o motivo da prisão." (Gardênia)

Outro fator elencado pelas presidiárias como agentes favorecedores do abandono familiar é a revista íntima, que é um requisito para o ingresso do familiar na unidade prisional, este procedimento causa em muitos dos visitantes um sentimento de violação em sua dignidade, pois se veem física e psicologicamente invadidas em sua intimidade visto que é necessário expor partes intimas de seu corpo a estranhos ${ }^{24}$. Há, nessa circunstância, a transmissão da pena da pessoa presa a inocentes, de forma a causar constrangimentos e estigmatização dos familiares ${ }^{25}$. Como podemos observar na fala a seguir:

"Não quero que a minha família venha a prisão devido a humilhação que ocorre durante a revista íntima e a humilhação que a família passa quando cruzam os portões para dentro da penitenciária." (Lírio)

"O constrangimento de passar pela revista que é muita humilhação pra família de gente." (Girassol)

O distanciamento, assim, por si só, teria como efeito maléfico direto a desestruturação das relações familiares. Esse prejuízo, porém, não apenas é objeto de pouca atenção como se vê ampliado por aspectos como a distância física entre as prisões e os polos urbanos e as restrições de horários e formas de visitação ${ }^{18}$. Como regra, passa a ser escassa a preocupação com a viabilidade do translado necessário à realização da visita. Por outro lado, mas no mesmo rumo, o ingresso dos familiares de presos nos espaços carcerários acaba por trazer, dados seus procedimentos, constrangimento a quem não foi condenado. Emblemática, aqui, é a questão da revista íntima, comumente feita em ocasião desnecessária e de modo degradante ${ }^{25}$.

Algumas presidiárias afirmam que as despesas com o deslocamento para a visita pesam no orçamento familiar. $\mathrm{O}$ gasto semanal com a visitação pode impactar o orçamento domestico destas famílias, considerando que em sua grande maioria sobrevivem com pequenos recursos financeiros ${ }^{18}$. Percebemos isso a seguir:

"A condição financeira também, porque minha família é de Sousa, aí fica ruim pra vim." (Girassol) 
"Por causa que eles não tem condições. Os outros porque moram em Pernambuco. Por causa do uso de drogas também e por causa do financeiro e porque nos também apronta muito." (Flor-de-lis)

“No meu caso eles também não vem aqui porque é distante, não tem dinheiro sabe. E não tem como. Eu entendo. Mas também não vou dizer que isso somente é uma desculpa." (Jasmin)

Outro aspecto que também foi levado em consideração pelas apenadas é o ambiente estressor que envolve a superlotação, agressões e a falta das assistências preconizadas pela Lei de Execuções Penais ${ }^{25}$. Isto é evidenciado na seguinte fala:

"Acho que o ambiente da prisão não ajuda ninguém a nada. Aí também o ambiente não ajuda a gente a ter uma convivência com a família. Nem ajuda as mães que estão presas a conviver com seus filhos... Aí os filhos abandonam as mães..." (Tulipa)

Diante do exposto, percebe-se que, não são poucos os entraves elencados como agentes favorecedores do abandono familiar, o que leva a um desamparo da família temporário ou definitivo acarretando na quebra dos vínculos familiares ${ }^{25}$.

Neste sentido, evidencia-se não apenas necessária, mas urgente, a implementação de medidas de promoção à melhoria dos vínculos entre familiares tais como: o cumprimento da pena próximo a seus familiares pois contribui para ressocialização e está preconizado pela Declaração Universal dos Direitos Humanos; o estímulo à prática de atividade laboral das apenadas que favoreça sua autoestima, propiciando renda para colaborar com custeio e manutenção do lar/filhos e fortalecer o núcleo já que a prisão causa importantes rearranjos nas relações sociais; a estruturação do sistema carcerário para garantir as saídas temporárias previstas que favorecem a permanência dos vínculos afetivos familiares para aquelas que cumprem pena em regime semi-aberto, salvaguardando o recomendado pela lei; e, a valorização/reconhecimento das atividades de assistência social, garantidas em lei, que ofertam possibilidades para harmônica integração social, construindo espaços que possibilitem aos reeducandos/famílias o diálogo na nova forma de vida.

No que tange ao ambiente prisional, revela-se como desafio educar as famílias e, por conseguinte, à sociedade para conviver com reeducandos e egressos do sistema carcerário. Nesse sentido, a vivência acadêmica dos estágios supervisionados das universidades pode favorecer uma aproximação com a realidade vivida pelos reeducandos e estimular treino de habilidades e competências nas diversas áreas do conhecimento que envolva as ciências humanas, sociais e da saúde.

Por fim julga-se oportuno sensibilizar os profissionais que trabalham nas unidades prisionais para prática do acolhimento, com postura ética que implica na escuta atenta, no reconhecimento do seu protagonismo no processo de saúde-doença e ressocialização, e na responsabilização pela resolução, com ativação de redes de compartilhamento de saberes. No cenário das penitenciárias acolher é um compromisso de resposta às necessidades das famílias e reeducandos que procuram os serviços de saúde.

Por se tratar de um ambiente prisional a presença da agente penitenciária durante a entrevista se constituiu como limitação desta pesquisa, visto que as presidiárias podem ter se sentido constrangidas de discorrerem sobre um tema tão subjetivo e particular.

Almeja-se que os conhecimentos produzidos a partir desta pesquisa permitam a otimização de políticas públicas direcionadas para a realização de uma assistência social voltada às mulheres presidiárias, e reforce a importância da família no processo de ressocialização, pois o apoio familiar se caracteriza enquanto impulsor de mudanças, bem como em refúgio emocional no período de encarceramento. Isto deve ser realizado em um trabalho multidisciplinar através de educação/conscientização da importância da participação ativa da família e implementação de um ambiente favorável às visitas, de uma forma acolhedora e que inspire segurança.

\section{CONSIDERAÇÕES FINAIS}

Para as participantes deste estudo a família representa um importante suporte afetivo e elo social, de modo que o abandono familiar no período do aprisionamento associa-se ao sofrimento, ao desamparo e a solidão.

As falas evidenciam que a dificuldade da família em perdoar o envolvimento das participantes do estudo com a criminalidade, os problemas financeiros e o constrangimento gerado, pela revista vexatória dos pertences, que antecede as visitas são, reconhecidamente os fatores que determinam e justificam o abandono familiar. Todavia reconhecem que este abandono interfere na qualidade de vida, interferindo no seu processo de ressocialização.

\section{REFERÊNCIAS}

1. Infopen. Mulheres Presas - dados gerais. Projeto Mulheres/DEPEN, Departamento Penitenciário Nacional. Brasília (DF): Ministério da Justiça; 2011.

2. Melo DC, Gauer G. Vivências da maternidade em uma prisão feminina do Estado do Rio Grande do Sul. Sau \& Transf Soc. 2011; 1(3):113-21. 
3. Santa Rita RP. Mães e crianças atrás das grades. Rev Sociologia Jurídica. 2006;03:10-9.

4. Stella C. Children of jailed women: the role of the mother in the socialization of individuals. Estud Pesqui Psicol. 2009;9(2).

5. Centro pela Justiça e pelo Direito Internacional. Relatório sobre mulheres encarceradas no Brasil. São Paulo: Instituto Brasileiro de Ciências Criminais; 2007.

6. Hermeto EMC, Sampaio JJC, Carneiro C. Abandono do uso de drogas ilícitas por adolescente: importância do suporte familiar. Rev Baiana Saúde Pública. 2010;34(3):639-52.

7. Oliveira LO, Costa GMC, Medeiros KKAS. Envelhecimento: significado para idosos encarcerados. Rev Bras Geriatr Gerontol. 2013;16(1):139-48. http://dx.doi.org/10.1590/S1809-9823201 3000100014

8. Brasil. Ministério da Saúde. Agenda Nacional de Prioridades e Pesquisa em Saúde. Série B. Textos Básicos em Saúde. Brasília (DF): Ministério da Saúde; 2008.

9. Fontanella BJB, Luchesi BM, Saidel MGB, Ricas J, Turato ER, Melo DG. Amostragem em pesquisas qualitativas: proposta de procedimentos para constatar saturação teórica. Cad Saúde Pública 2011;27(2):38894. http://dx.doi.org/10.1590/S0102$311 \times 2011000200020$

10. Bardin L. Análise de conteúdo. São Paulo: Ed. 70; 2011.

11. Miguel LOS, Braga ERM. A importância da família no processo de aprendizagem, visando ao sucesso escolar. Maringá (PR): Universidade Estadual de Maringá; 2009.

12. Durman S, Piccoli M, Shneider JF, Stefanelli MC. Discursos de estudantes de enfermagem sobre família. Acta Sci Health Sci. 2004; 26(1):47-51. http://dx.doi.org/10.4025/actascihealthsci.v26i1.1616

13. Pedreira LC, Oliveira AMS. Cuidadores de idosos dependentes no domicílio: mudanças nas relações familiares. Rev Bras Enferm. 2012;65(5):730-6. http://dx.doi.org/10.1590/S003471672012000500003
14. Oliveira NHD. Recomeçar: família, filhos e desafios. São Paulo: Cultura Acadêmica; 2009.

15. Gomes MA, Pereira MLD. Família em situação de vulnerabilidade social: uma questão de políticas públicas. Ciênc Saúde Coletiva 2005;10(2):357-63. http://dx.doi.org/10.1590/S141381232005000200013

16. Fernandes R, Hirdes A. A percepção dos apenados a respeito do cárcere e da privação da liberdade. R Enferm UERJ. 2006;14(3): 418-24.

17. Galvão MCB, Davim RMB. Vivência de mulheres encarceradas durante a gestação. Rev Enferm UFPE. 2014;8(supl. 1):2272-80.

18. Heredia VBM, Cortelletti IA, Casara MB. Abandono na velhice. Textos Envelhecimento [online]. 2005 [citado 03 fev. 2014];8(3).

19. Soares BM, Ilgenfritz I. Prisioneiras: vidas e violências atrás das grades. Rio de Janeiro: Garamond; 2002.

20. Gomes ABF. As prisões do feminino e as mulheres nas prisões: um recorte sobre a maternidade encarcerada. Rio de Janeiro: UFF; 2010.

21. Frinhani FMD, Souza L. Mulheres encarceradas e espaço prisional: uma análise de representações sociais. Psicol Teor Prat. [Internet].2005 [citado 27 jan. 2013];7(1):61-79.

22. Martins EMCS, Ataíde MBC, Silva DMA, Frota MA. Vivência de mães no cuidado à criança diabética tipo I. Rev Rene. 2013;14(1):42-9.

23. Ferrari IF. Mulheres encarceradas: elas, seus filhos e nossas políticas. Rev Mal-estar Subjetiv [Internet]. 2010 [citado 22 out. 2013]; 10(4):1325-52.

24. Colmeia, Z. Família e Cárcere: os efeitos da punição sobre a unidade familiar e a necessidade de inclusão. Trabalho Forense. Boletim do Centro de Apoio Operacional das Promotorias Criminais, do Júri e de Execuções Penais - Área de Execução Penal no 86 maio/2011.

25. Santos BS. A reinserção social dos reclusos: um contributo para o debate sobre a reforma do Sistema Prisional. Coimbra: Universidade de Coimbra; 2003. 